\title{
Tcf7l1 directly regulates cardiomyocyte differentiation in embryonic stem cells
}

\author{
Rui Liang and Yu Liu* (D)
}

\begin{abstract}
The T-cell factor/lymphoid enhancer factor (TCF/LEF) family protein Tcf7l1 is highly abundant in embryonic stem cells (ESCS), regulating pluripotency and preparing epiblasts for further differentiation. Defects in the cardiovascular system in Tcf7l1-null mouse were considered secondary to mesoderm malformation. Here, we used temporally controlled Tcf7|1 expression in Tcf7/1-null ESCs to address whether Tcf7|1 directly contributes to cardiac forward programming. Tcf7l1 knockout during differentiation impaired cardiomyocyte formation but did not affect mesoderm formation. Tcf7/1-null ESCs showed delay in mesoderm formation, but once completed, ectopic Tcf7|1 augmented cardiomyocyte differentiation. Further, Tcf7|1-VP16 and Tcf7|1dN showed procardiac activity whereas Tcf7l1-En was ineffective. Our results support that Tcf7l1 contributes to cardiac lineage development as a $\beta$-catenin-independent transactivator of cardiac genes.
\end{abstract}

Keywords: Wnt, $\beta$-Catenin, T-cell factor/lymphoid enhancer factor, Tcf3, Cardiac myocytes

\section{Introduction}

The Wnt/ $\beta$-catenin signaling pathway is critical in stem cell pluripotency, differentiation and homeostasis $[1,2]$. In the absence of WNT ligand, $\beta$-catenin is phosphorylated by a destruction complex composed of adenomatous polyposis coli (APC), glycogen synthase kinase 3 (GSK3), and kinases casein kinase 1 (CK1) [3]. Phosphorylated $\beta$-catenin is ubiquitinated and degraded by proteasomes. WNT ligand binding disaggregates the destruction complex, and in turn stabilizes $\beta$-catenin. Next, $\beta$-catenin is translocated into the nucleus where it binds T-cell factor/lymphoid enhancer factor (TCF/LEF) family proteins to transactivate downstream genes [4]. The Wnt/ $\beta$-catenin pathway plays a biphasic role in cardiogenesis: an initial activation phase in which $\mathrm{Wnt} / \beta$-catenin promotes mesoderm formation, followed by an inhibitory phase in which the pathway is shut off to allow cardiac gene expression.

There are four TCF/LEF family proteins in mammals: TCF7, LEF1, TCF711, and TCF712 [5]. They bind the consensus DNA element 5'-(A/T)(A/T)CAAAG-3' [3, 4]. Their interactions with both $\beta$-catenin and the

\footnotetext{
* Correspondence: yliu54@uh.edu

Department of Biology and Biochemistry, University of Houston, Houston, TX 77004, USA
}

(c) The Author(s). 2018 Open Access This article is distributed under the terms of the Creative Commons Attribution 4.0 International License (http://creativecommons.org/licenses/by/4.0/), which permits unrestricted use, distribution, and

transregulatory element are necessary for activating target genes in response to WNT signaling [6-8]. In mouse genetic studies, only Tcf7l1 deletion led to severe embryonic defects and lethality. The defects are related to delayed mesoderm specification, axis mesoderm duplication, and impaired lateral mesoderm formation. Some severely affected embryos display enlarged cardiac sacs, missing hearts, and multiple large blood vessels [9]. In embryonic stem cells, Tcf7l1 negatively modulates the expression of pluripotent genes, and prepares the epiblast for transition to lineage specification [10-12]. It has been reported that Tcf7l1 can function independently of $\beta$-catenin during gastrulation and hypothalamopituitary $(\mathrm{HP})$ axis formation $[3,4,13]$. Because of defective mesoderm formation, whether Tcf7l1 intrinsically contributes to cardiac development has not been determined in $T c f 7 l 1^{-1-}$ embryos.

Herein, based on a $T c f 7 l 1^{-1-}$ background, we conducted temporally controlled Tcf7l1 rescuing experiments, and demonstrate that Tcf7l1 acts as an activator-like transcription factor and regulates cardiac lineage development independent of $\beta$-catenin.

\section{Materials and methods \\ Cell culture}

Tcf $7 l 1^{+/+}$and $T c f 7 l 1^{-1-}$ ESC lines were provided by Dr Bradley J. Merrill (University of Illinois at Chicago, 
USA). ESCs were propagated in $0.1 \%$ gelatin-coated dishes and cultured with feeder-free ESC medium (DMEM (Gibco) supplemented with 15\% FBS (Atlanta Biologicals), $100 \mathrm{U} / \mathrm{ml}$ penicillin $\mathrm{G}, 100 \mu \mathrm{g} / \mathrm{ml}$ streptomycin sulfate, $2 \mathrm{mM}$ l-glutamine, $0.1 \mathrm{mM} \beta$-mercaptoethanol, $1 \times$ $103 \mathrm{U} / \mathrm{ml}$ murine leukemia inhibitory factor (LIF; Global Stem)). The medium was changed daily. To induce EB formation and differentiation, the ESCs were grown as $20 \mu \mathrm{l}$ hanging droplets $\left(2 \times 10^{4}\right.$ cells $\left./ \mathrm{ml}\right)$ in SFDM without LIF [1]. EBs were collected as indicated and the medium was replaced every 2 days. 293FT cells were cultured in DMEM (Gibco) supplemented with 20\% FBS (Atlanta Biologicals), $100 \mathrm{U} / \mathrm{ml}$ penicillin $\mathrm{G}, 100 \mu \mathrm{g} / \mathrm{ml}$ streptomycin sulfate, and $2 \mathrm{mM}$ l-glutamine.

Construction of the inducible expression vector, preparation of lentiviral vectors, and selection of stable expression clones

We used the Tet-On advanced lentiviral vector system (Clontech) and the Tet-Off advanced lentiviral vector system (Clontech) for inducible gene expression. Tcf7l1 and Tcf7lldN (N-ter 73 amino acid deletion) genes were amplified by PCR from Homo sapiens transcription factor 7-like 1 cDNA clone (OriGene Technologies) using Pfx DNA Polymerase (Invitrogen). Tcf711-VP16 was prepared by fusing aa 314-471 of Tcf711 to the VP16 activation domain. Tcf7l1-En was prepared by fusing aa 314471 of Tcf7l1 to the repressor domain of Engrailed 1.

Additional materials and methods are presented in Additional file 1: Supplemental information.

\section{Results}

The Tcf7l1 ${ }^{-1-}$ ESC has a 64-bp deletion in exon 2 of the Tcf7l1 gene, causing a frameshift and an early termination in translation. Thus, the $T c f 7 l 1^{-1-}$ cell does not express detectable Tcf7l1 (Fig. 1a) [9]. Compensatory upregulation was detected for Tcf7 and Tcf7l2, but not for Lef1 (Additional file 2: Figure S1A). We compared the differentiation course of wildtype $\mathrm{Tcf}_{\mathrm{f}} \mathrm{l1} 1^{+/+}$and $T c f 7 l 1^{-1-}$ ESCs using the standard embryoid body (EB) culture protocol. Pluripotent genes Oct4 and Sox2 decreased during the course of differentiation in $T c f 7 l 1^{+/+}$ cells, but were maintained in $T c f 7 l 1^{-1-}$ ESCs. At later time points, the expression of Oct4 and Sox 2 was significantly higher in $T c f 7 l 1^{-1-}$ cells (Fig. 1b), suggesting that deletion of Tcf7l1 causes a delay in exiting the pluripotent state. To determine the effects of Tcf7l1 ablation on lineage commitment, we examined the expression of mesoderm and endoderm markers. Brachyury/T was

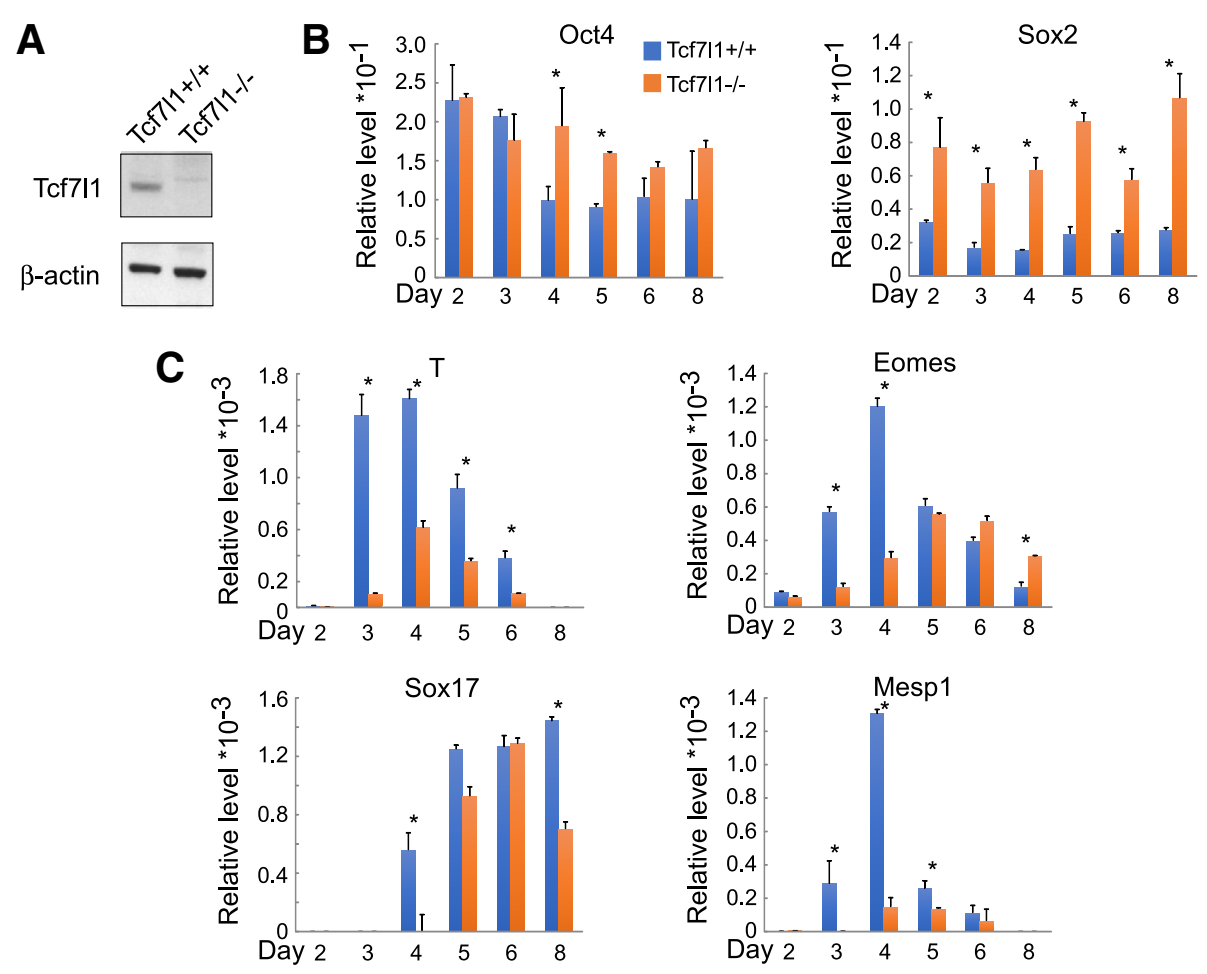

Fig. 1 Genetic ablation of Tcf7l1 leads to delayed and partially blocked mesendoderm formation. a Western blot confirmation of Tcf7l1 absence in $T c f 7 / 1^{-/-}$ESCs. b Downregulation of Oct4 and Sox2 during differentiation is impaired in $T c f 7 / 1^{-/-}$ESCs. c Expression of mesendoderm genes, $T$, Eomes, Sox 17, and Mesp 1, is delayed and partially reduced in Tcf711 ${ }^{-1-}$ ESCs. Gene expression assayed by real-time RT-PCR. $N \geq 3$; ${ }^{*} p<0.05$ versus control cells 
significantly lower at all time points, while Eomes, Sox17, and Mesp1 showed delayed and lower expression levels in Tcf7l1 $1^{-1-}$ ESCs (Fig. 1c). These data suggest that Tcf7l1 ablation causes a significant delay and incomplete blockage in ESC differentiation.

To determine whether Tcf7l1 is also required for cardiomyocyte formation, in addition to its essential role in transition from pluripotency to differentiation, we engineered a novel ESC model in which Tcf7l1 expression can be ablated in a temporally controlled fashion: into $T c f 7 l 1^{-1-}$ ESCs, we introduced a tetracycline response element (TRE)-controlled Tcf7l1 transgene along with a tetracycline-controlled transactivator ( $\mathrm{tTA})$ transgene (Fig. 2a). In this model, supplemental doxycycline (dox) silences Tcf7l1 transgene expression, hence achieving "knock out" (Tcf7l1-tetoff) (Fig. 2b, Additional file 2: Figure S1B). Without dox, the transgene allowed differentiation into cardiomyocytes, evidenced by expression of the cardiac mesoderm marker Mesp1 at day 6 and of cardiomyocyte genes $T b \times 5, N k x 2-5$, and $\alpha M H C$ at days 8 and 9. Next, we compared the differentiation outcome of Tcf7l1 ablation since days 2, 4, 6, and 8 (Fig. 2c-e). Tcf7l1 ablation since day 2 or 4 significantly reduced the expression of Mesp1, Tbx5, Nkx2-5, and $\alpha M H C$, whereas ablation since day 6 only significantly reduced $\alpha M H C$, suggesting the expression of these genes is dependent on Tcf7l1 (Fig. 2e). Consistently, Tcf7l1 ablation since day 2 or 4 reduced cardiac $\alpha$-Actinin-positive cardiomyocyte formation (Fig. 2d). To determine whether the impaired cardiomyocyte formation is secondary to defects in mesoderm and endoderm development, we tested the expression of T, Eomes, Gsc, and Sox17. Tcf7l1 ablation since day 2 or 4 increased the expression of T, Eomes, and Gsc, supporting that mesoderm and endoderm development are largely intact (Fig. 2f). The increased levels may be secondary to blocked downstream differentiation. In contrast, Sox17 was downregulated upon Tcf711 ablation, consistent with our previous finding that Sox17 relays cardiogenic signals in the endoderm. We found no changes in early neural markers (Notch3, Pax6, and Nestin) (Fig. 2g), the smooth muscle/myofibroblast marker ACTA2, or the panendothelial marker PECAM-1 upon Tcf7l1 ablation (data not shown), indicating that its obligatory role in cardiomyocyte formation is lineage specific.

Next, we addressed whether the transcription repressor or activator role of Tcf7l1 is involved in activating the cardiomyocyte program. Into $T c f 7 l 1^{-/-}$ESCs, we introduced three versions of Tcf7l1 transgene: wildtype; Tcf711-VP16, a fusion between the Tcf7l1 DNA-binding domain and the VP16 transactivation domain; and Tcf7l1-En, a fusion between the Tcf7l1 DNA-binding domain and the Engrailed repression domain (Additional file 3: Figure S2A). The differentiation timing of the ESCs receiving these transgenes varied, but it was consistent that ESCs expressing Tcf7l1-VP16 showed significantly increased mesodermal markers ( $T$ and Mesp1) compared to ESCs expressing Tcf7l1-En (Additional file 3: Figure S2B). Slightly increased expression of $N k x 2-5$ but little effect on Sox17 was also present. Earlier work in our laboratory [14] established that TCF/LEF proteins cooperate with Oct4 to drive the transcription of Mesp1. The significant upregulation of Mesp1 by Tcf7l1-VP16 suggests that Tcf711 may be the responsible TCF/LEF protein.

To further address whether Tcf7l1 is sufficient in triggering the cardiomyocyte differentiation program, we engineered additional ESC models in which Tcf711 expression can be activated in a temporally controlled fashion. Into $T c f 7 l 1^{-1-}$ ESCs, we introduced a TRE-controlled Tcf7l1 transgene along with a reverse tetracycline-controlled transactivator (rtTA) transgene (Fig. 3a). The Tcf7l1 transgene is only expressed upon dox supplement (teton). To gain mechanistic insights into the effect of Tcf71, we compared four versions of Tcf7l1: wildtype (wt), mutant with an N-ter deletion abolishing its interaction with $\beta$-catenin (Tcf7lldN), Tcf711-VP16, and Tcf711-En. Dox supplement for $24 \mathrm{~h}$ activated protein expression of the four versions of $T c f 7 l 1$ transgene, with undetectable background (Fig. 3b).

We chose to activate ectopic Tcf7l1 expression at day 7 , when $T c f 7 l 1^{-1-}$ cells have passed the stage of mesoderm formation (Fig. 3c-f). This allowed us to evaluate the effect of Tcf7l1 transgenes on cardiomyocyte differentiation. By assaying the cardiac gene $N k x 2-5$, only Tcf7l1dN and Tcf7l1-VP16 activated the cardiomyocyte program (Fig. 3f). Tcf7l1-En downregulated $N k \times 2-5$. In immunostaining of $\alpha$-Actinin, Tcf7l1dN and Tcf7l1-VP16 boosted formation of sarcomeric structures but not Tcf7l1-En (Fig. 3d, e). Ectopic wildtype Tcf7l1 did not activate Nkx2-5 expression, consistent with the notion that Tcf7l1 is a weaker transactivator compared to Tcf7 and Lef1 [15, 16]. Both Tcf7l1dN and Tcf7l1-VP16 showed more pronounced effects, perhaps because these variants have acquired higher transactivating capacity. These data support our hypothesis that transactivating activity of Tcf7l1 directly contributes to cardiac linage development. Moreover, the de-novo function of Tcf7l1 does not require its interaction with $\beta$-catenin in cardiomyocyte differentiation.

Finally, we tested whether Tcf7l1 directly transactivates important lineage-determining genes in the cardiomyocyte differentiation program. Based on results from a previous whole-genome survey of Tcf7l1-binding sites $[17,18]$, we selected a number of cardiac genes for chromatin immunoprecipitation PCR (ChIP-PCR) confirmation. Endogenous Tcf7l1 ChIP-PCR revealed enrichment in Mesp1, Gata4, Mef2C, as well as $\alpha M H C$, 
A

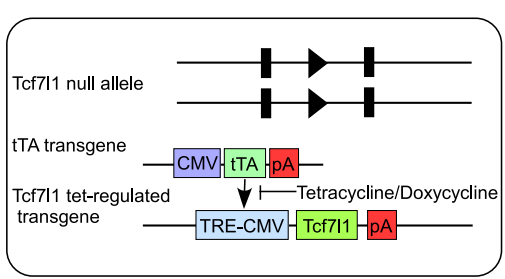

C

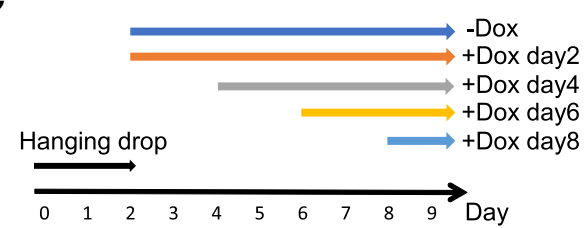

B

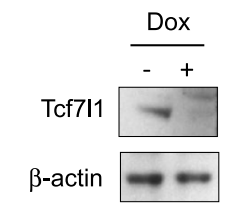

D

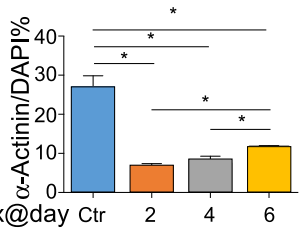

E
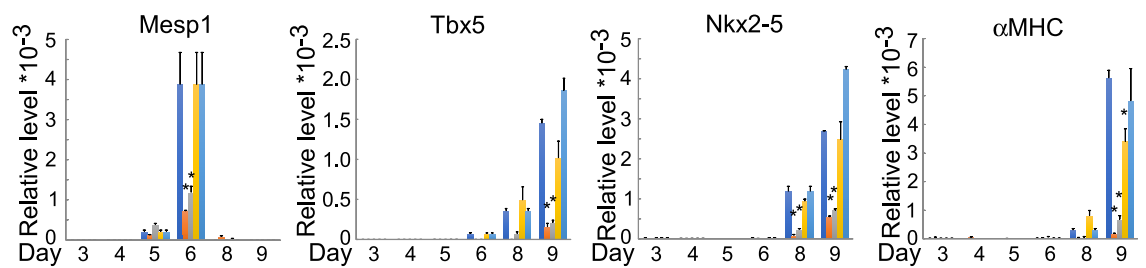

F

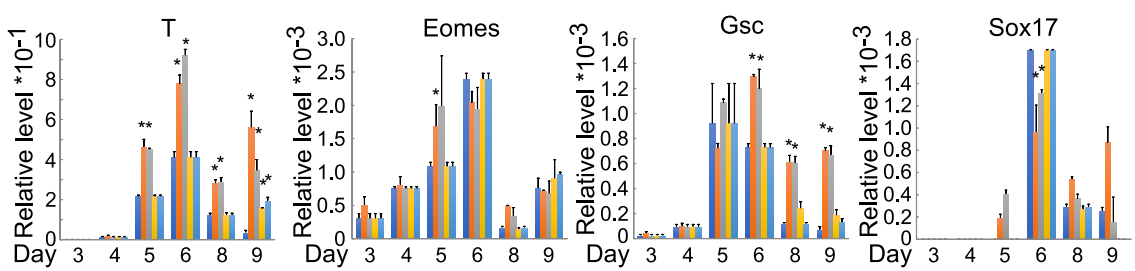

G

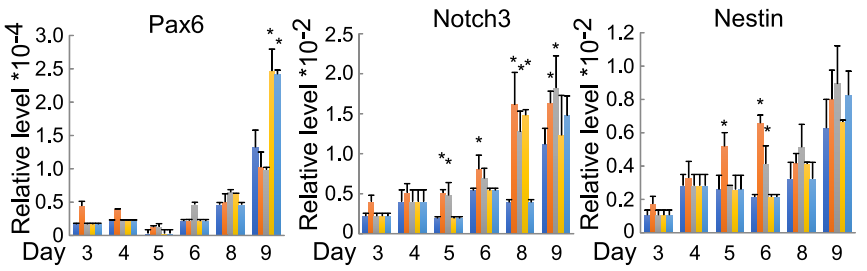

Fig. 2 Temporally controlled ablation of Tcf7l1 impaired cardiomyocyte formation without affecting germ layer differentiation. a Genetic elements in Tcf7l1-tetoff ESCs. Two transgenes introduced into Tcf7/1 ${ }^{-1-}$ ESCs: tetracycline-controlled transactivator (tTA) driven by CMV promoter and Tcf7l1 driven by tetracycline responsive promoter (TRE-CMV). Presence of tetracycline or doxycycline blocks activity of tTA transactivator, hence silencing Tcf7l1 transgene. b Western blot confirmation of Tcf7l1 transgene silencing by supplemental dox. c Scheme of dox supplementation. d Ablation of Tcf $7 / 1$ at days 2 and 4 impaired cardiomyocyte formation, evidenced by reduced positive staining for a-Actinin. e Cardiac mesoderm marker Mesp1, cardiac transcription factors Tbx5 and Nkx2-5, and cardiac structural gene aMHC reduced by Tcf7l1 ablation at days 2 and 4, but not ablation at days 6 and 8. f Nascent mesendoderm genes T, Eomes, and Gsc elevated, whereas Sox 17 reduced upon Tcf7l1 ablation at days 2 and 4. g Ectoderm genes Pax6, Notch3, and Nestin showed increased expression upon Tcf7l1 ablation at several time points. Gene expression assayed by real-time RT-PCR. $N \geq 3$; ${ }^{*} p<0.05$ versus control cells. CMV cytomegalovirus, Ctr control, DAPI 4,6-diamidino-2-phenylindole

which are core cardiac transcription factor and structural genes (Fig. 4a). Pulling-down ectopic Tcf7l1 in Tcf $7 l 1^{-1-}$ ESCs also enriched Mesp1, Gata4, Mef2C, and $\alpha M H C$ genes (Fig. 4b). Tcf7l1 stimulated the Mesp1-Luc reporter in a dose-dependent manner, supporting that Tcf7l1 functions as a Mesp1 transactivator (Fig. 4c). These data suggest that Tcf7l1 directly binds Mesp1 and other important cardiac transcription factors in driving cardiomyocyte differentiation.

\section{Discussion}

The development of the cardiovascular system requires precisely regulated canonical WNT signaling $[19,20]$. As an important downstream factor of WNT, Tcf7l1 is critical in maintaining pluripotency as well as preparing ESCs for gastrulation $[21,22]$. However, the function of Tcf7l1 in cardiomyocyte differentiation was unknown, mainly because $\mathrm{KO}$ of Tcf7l1 impairs prerequisite steps. In this study, we demonstrate that Tcf7l1 is intrinsically required 
A

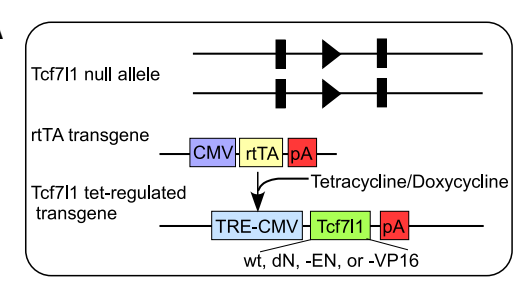

C

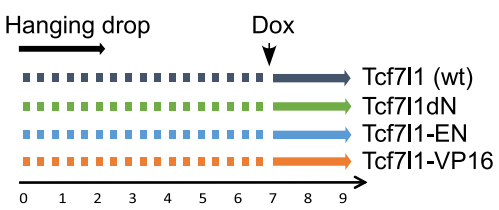

E

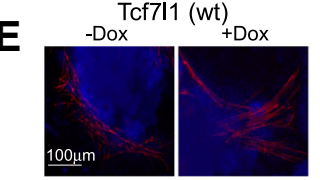

$\mathbf{F}$

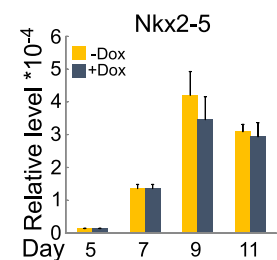

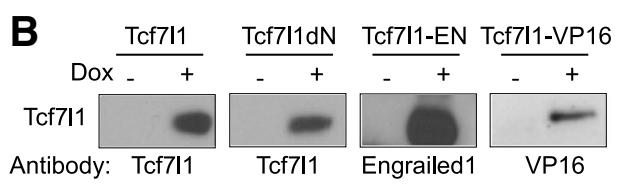
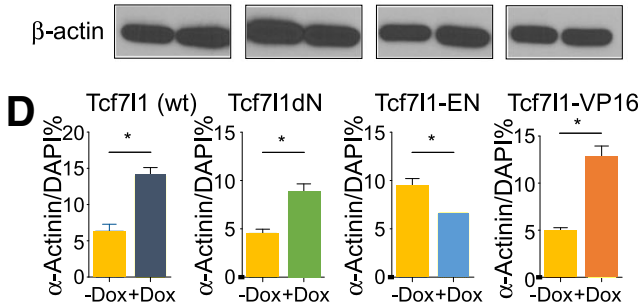

Tcf7I1-EN
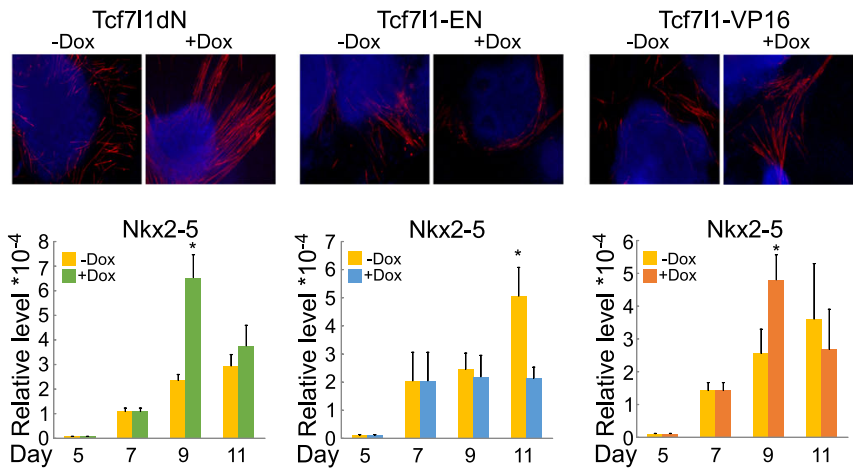
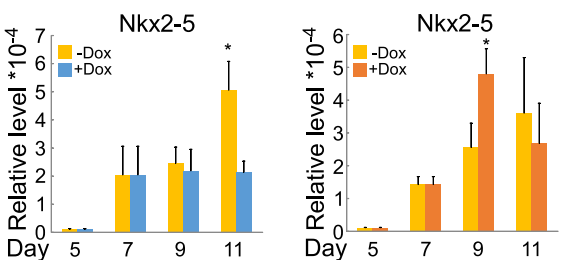

Fig. 3 -Catenin-independent transactivator activity of Tcf7l1 contributes to cardiomyocyte programming. a Genetic elements in Tcf7l1-teton ESCs. Endogenous Tcf7l1 alleles are null. Reverse tetracycline-controlled transactivator (rtTA) transgene driven by CMV promoter. Tcf7l1 transgene driven by tetracycline responsive promoter TRE-CMV. In presence of tetracycline/doxycycline, Tcf7l1 transgene is transactivated. Four versions of Tcf7|1 (wt, Tcf7|1 dN, Tcf7|1-En, and Tcf7|1-VP16) transgenes compared. b Western blot confirmation of transgene induction by 24-h supplemental dox. c Scheme of dox supplementation. $\mathbf{d}$ Tcf $71 \mathrm{dN}$ and Tcf7l1-VP16 augmented formation of a-Actinin-positive cardiomyocytes. e Representative a-Actinin staining results of (c). $\mathbf{f} T c f 711 \mathrm{dN}$ and Tcf711-VP16 upregulated Nkx2-5 expression, whereas Tcf7|1-En downregulated it. Nkx2-5 gene expression assayed by real-time RT-PCR. $N \geq 3 ;{ }^{*} p<0.05$ versus control cells. CMV cytomegalovirus, DAPI 4',6-diamidino-2-phenylindole, wt wildtype

for the establishment of the cardiomyocyte linage. Our data support that Tcf7l1 contributes to cardiac lineage development as a $\beta$-catenin-independent transactivator for Mesp1 and other cardiac lineage-determining genes.

The TCF/LEF family members play important but distinctive roles in embryonic development. Tcf7 is essential for thymocyte differentiation. Homologous deletion of Lef1 led to missing teeth, mammary glands, whiskers, and hair. Tcf7l2 is obligatory for formation of epithelial stem cells in the small intestine. The role and underlying mechanisms of Tcf7l1 are stage dependent and very enigmatic. Tcf7l1 is important for pluripotency maintenance, mesoderm induction, and further specification. It may be specifically required for heart formation: mildly affected Tcf7l1 null mutants had enlarged hearts, while severely affected mice fail to develop the heart. Our work provides a first-degree approximation of how Tcf711 may affect cardiomyocyte formation. The ESC models established in this study may be useful in conditionally manipulating Tcf7l1 expression at the organism level. It was previously reported that Tcf7l1 restricts cardiomyocytes while promoting endothelial specification in zebrafish [23]. Although Tcf7l1 may play different roles in these two species, it is more likely that the loss of Tcf7l1 has triggered compensation by other TCF/LEF factors and the phenotypes reflect varied overall effects. To this end, Moreira et al. [24] demonstrated that a single TCF/LEF factor is sufficient for trilineage differentiation in ESCs, but how the stoichiometry of TCF/LEF factors contributes to cell fate specification and organogenesis warrants additional investigation.

Previous studies have found that Tcf7l1 protein mostly act as a transcriptional repressor, in the absence of $\beta$-catenin $[9,22,25-28]$. $\beta$-catenin binding releases the repression activity of Tcf7l1, thus maintaining pluripotent cell renewal and triggering gastrulation. However, $\beta$-catenin binding seems unessential for gastrulation, as knockin Tcf7l1 $\Delta \mathrm{N}$ mutant mice gastrulate normally [3]. In this study, Tcf7l1 worked as a $\beta$-catenin-independent transactivator because only Tcf7l1dN and Tcf7l1-VP16 


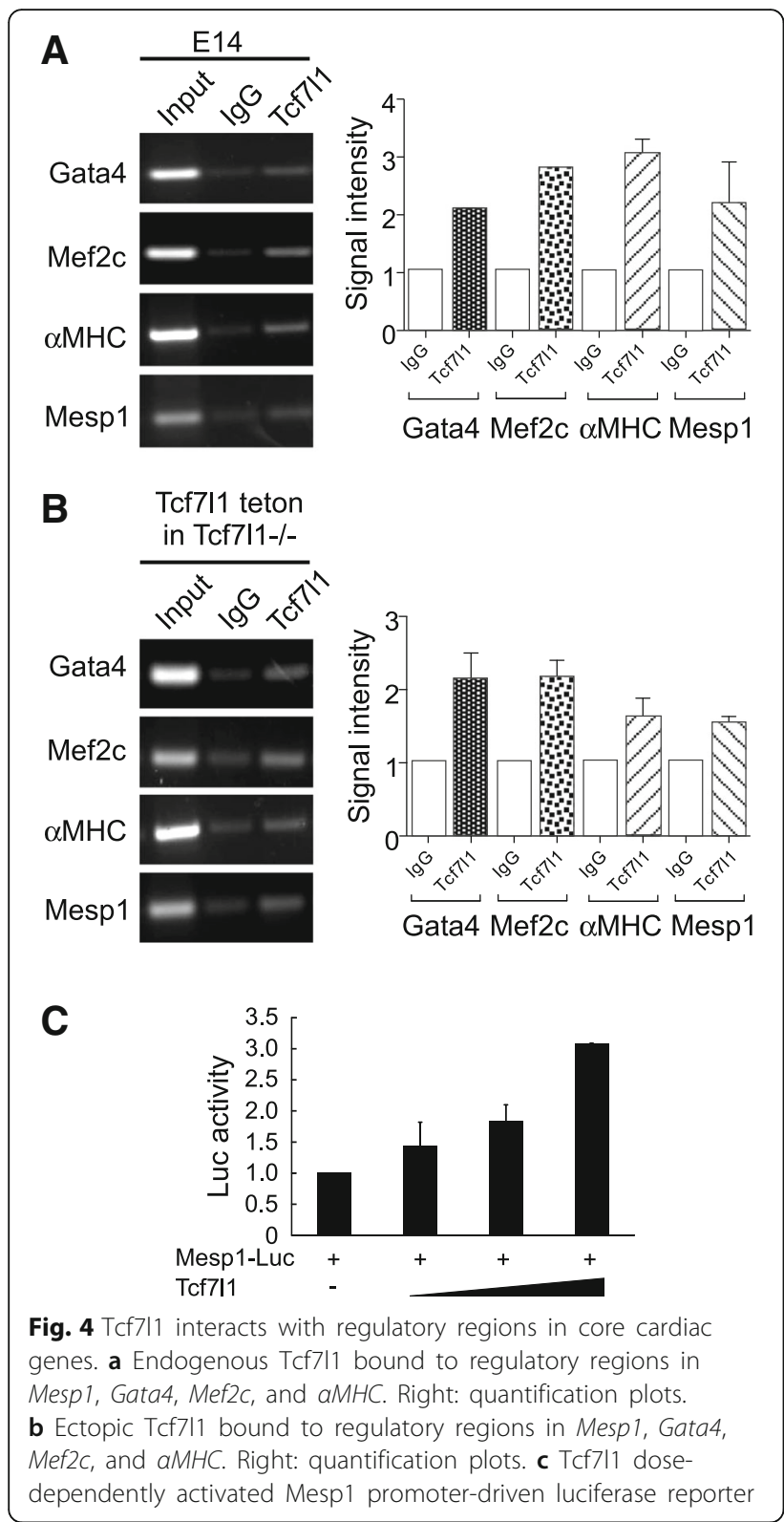

rescued $T c f 7 l 1^{-1-}$ cells for cardiomyocyte differentiation. Although current literature leans heavily toward repressor activity of Tcf7l1, emerging evidence supports that it can also function as a transactivator. It induces LCN2 expression in a $\beta$-catenin-independent fashion and drives skin carcinogenesis [29]. Whether the transactivator function of Tcf7l1 requires other cofactors remains unknown.

Both opposite and compensatory effects among the TCF/LEF family members exist in developmental processes, but we were unable to address such effects in this study. Further study is needed to investigate the function of other individual TCF/LEF members, as well as the mechanism of their balanced relationships during cardiomyocyte differentiation.

\section{Additional files}

Additional file 1: Supplemental information. (PDF $179 \mathrm{~kb}$ )

Additional file 2: Figure S1. (A) Expression of Tcf7, Lef1, and Tcf7l2 in TCf $7 / 1^{-1-}$ ESCs. (B) Comparison of conditional transgene expression levels to those in wildtype ESCs. In both Tet-On and Tet-Off systems, expression of transgene is within a comparable range to those in wildtype ESCs (PDF $1121 \mathrm{~kb}$ )

Additional file 3: Figure S2. Constitutive transactivator activity of Tcf7l1 augmented mesoderm markers. (A) Western blot confirmation of ectopic Tcf7l1 expression. (B) Differential effects of Tcf7l1-VP16 and Tcf7l1-En on expression of mesendoderm genes, $T$ and Mesp 1, and cardiac transcription factor Nkx2-5. Gene expression assayed by real-time RT-PCR. $N \geq 3$; ${ }^{*} p<0.05$ versus control cells (PDF $364 \mathrm{~kb}$ )

\section{Acknowledgements}

The authors thank Bradley Merrill for providing Tcf7l1 $1^{-/-}$embryonic stem cells, and David Stewart and Robert Schwartz for helpful discussions.

\section{Funding}

Supported by research funds from the University of Houston (to YL), and grants from the American Heart Association (11SDG5260033 and

16GRNT27760164 to YL) and the US Department of Defense Congressionally Directed Medical Research Programs (PR162075 to YL). The funding bodies do not have roles in the design of the study and collection, analysis, and interpretation of data and in writing the manuscript.

\section{Availability of data and materials}

All data generated or analyzed during this study are included in this published article and its Additional files.

\section{Authors' contributions}

$\mathrm{RL}$ was responsible for collection and/or assembly of data, data analysis and interpretation, and manuscript writing. YL was responsible for collection and/ or assembly of data, data analysis and interpretation, manuscript writing, and final approval of the manuscript. Both authors read and approved the final manuscript.

Ethics approval and consent to participate Not applicable.

\section{Consent for publication}

Not applicable.

\section{Competing interests}

The authors declare that they have no competing interests.

\section{Publisher's Note}

Springer Nature remains neutral with regard to jurisdictional claims in published maps and institutional affiliations.

Received: 20 July 2018 Revised: 18 September 2018 Accepted: 21 September 2018 Published online: 11 October 2018

\section{References}

1. Lu L, Gao Y, Zhang Z, Cao Q, Zhang X, Zou J, et al. Kdm2a/b lysine demethylases regulate canonical Wnt signaling by modulating the stability of nuclear beta-catenin. Dev Cell. 2015;33:660-74.

2. Hu B, Wang Q, Wang YA, Hua S, Sauve CG, Ong D, et al. Epigenetic activation of WNT5A drives glioblastoma stem cell differentiation and invasive growth. Cell. 2016;167:1281-1295 e18.

3. Wu Cl, Hoffman JA, Shy BR, Ford EM, Fuchs E, Nguyen $H$, et al. Function of Wnt/beta-catenin in counteracting Tcf3 repression through the Tcf3-betacatenin interaction. Development. 2012;139:2118-29.

4. Gaston-Massuet C, McCabe MJ, Scagliotti V, Young RM, Carreno G, Gregory LC, et al. Transcription factor 7-like 1 is involved in hypothalamo-pituitary axis development in mice and humans. Proc Natl Acad Sci U S A. 2016;113: E548-57. 
5. Ombrato L, Lluis F, Cosma MP. Regulation of self-renewal and reprogramming by TCF factors. Cell Cycle. 2012;11:39-47.

6. Behrens J, Jerchow BA, Wurtele M, Grimm J, Asbrand C, Wirtz R, et al. Functional interaction of an axin homolog, conductin, with beta-catenin, APC, and GSK3beta. Science. 1998;280:596-9.

7. Brannon M, Gomperts M, Sumoy L, Moon RT, Kimelman D. A beta-catenin/ XTcf-3 complex binds to the siamois promoter to regulate dorsal axis specification in Xenopus. Genes Dev. 1997;11:2359-70.

8. Molenaar M, van de Wetering M, Oosterwegel M, Peterson-Maduro J, Godsave S, Korinek V, et al. XTcf-3 transcription factor mediates betacatenin-induced axis formation in Xenopus embryos. Cell. 1996;86:391-9.

9. Merrill BJ, Pasolli HA, Polak L, Rendl M, Garcia-Garcia MJ, Anderson KV, et al. Tcf3: a transcriptional regulator of axis induction in the early embryo. Development. 2004;131:263-74.

10. Wray J, Kalkan T, Gomez-Lopez S, Eckardt D, Cook A, Kemler R, et al. Inhibition of glycogen synthase kinase-3 alleviates Tcf3 repression of the pluripotency network and increases embryonic stem cell resistance to differentiation. Nat Cell Biol. 2011;13:838-45.

11. Hoffman JA, Wu Cl, Merrill BJ. Tcf7l1 prepares epiblast cells in the gastrulating mouse embryo for lineage specification. Development. 2013; 140:1665-75.

12. Salomonis N, Schlieve CR, Pereira L, Wahlquist C, Colas A, Zambon AC, et al. Alternative splicing regulates mouse embryonic stem cell pluripotency and differentiation. Proc Natl Acad Sci U S A. 2010;107:10514-9.

13. Yi F, Merrill BJ. Stem cells and TCF proteins: a role for beta-cateninindependent functions. Stem Cell Rev. 2007;3:39-48.

14. Li Y, Yu W, Cooney AJ, Schwartz RJ, Liu Y. Brief report: Oct4 and canonical Wnt signaling regulate the cardiac lineage factor Mesp1 through a Tcf/LefOct4 composite element. Stem Cells. 2013;31:1213-7.

15. Cadigan KM, Waterman ML. TCF/LEFs and Wnt signaling in the nucleus. Cold Spring Harb Perspect Biol. 2012;4. https://doi.org/10.1101/cshperspect.a007906.

16. Chodaparambil JV, Pate KT, Hepler MR, Tsai BP, Muthurajan UM, Luger K, et al. Molecular functions of the TLE tetramerization domain in Wnt target gene repression. EMBO J. 2014;33:719-31.

17. Marson A, Levine SS, Cole MF, Frampton GM, Brambrink T, Johnstone S, et al. Connecting microRNA genes to the core transcriptional regulatory circuitry of embryonic stem cells. Cell. 2008;134:521-33.

18. Martello G, Sugimoto T, Diamanti E, Joshi A, Hannah R, Ohtsuka S, et al. Esrrb is a pivotal target of the Gsk3/Tcf3 axis regulating embryonic stem cell self-renewal. Cell Stem Cell. 2012;11:491-504.

19. Kwon C, Cordes KR, Srivastava D. Wnt/beta-catenin signaling acts at multiple developmental stages to promote mammalian cardiogenesis Cell Cycle. 2008;7:3815-8.

20. Tzahor E. Wnt/beta-catenin signaling and cardiogenesis: timing does matter. Dev Cell. 2007;13:10-3

21. Yi F, Pereira L, Merrill BJ. Tcf3 functions as a steady-state limiter of transcriptional programs of mouse embryonic stem cell self-renewal. Stem Cells. 2008;26:1951-60

22. Yi F, Pereira L, Hoffman JA, Shy BR, Yuen CM, Liu DR, et al. Opposing effects of Tcf3 and Tcf1 control Wnt stimulation of embryonic stem cell selfrenewal. Nat Cell Biol. 2011;13:762-70.

23. Sorrell MR, Dohn TE, D'Aniello E, Waxman JS. Tcf7l1 proteins cell autonomously restrict cardiomyocyte and promote endothelial specification in zebrafish. Dev Biol. 2013;380:199-210.

24. Moreira S, Polena E, Gordon V, Abdulla S, Mahendram S, Cao J, et al. A single TCF transcription factor, regardless of its activation capacity, is sufficient for effective trilineage differentiation of ESCs. Cell Rep. 2017;20:2424-38.

25. Kim CH, Oda T, Itoh M, Jiang D, Artinger KB, Chandrasekharappa SC, et al. Repressor activity of Headless/Tcf3 is essential for vertebrate head formation. Nature. 2000;407:913-6.

26. Liu F, van den Broek O, Destree O, Hoppler S. Distinct roles for Xenopus Tcf/ Lef genes in mediating specific responses to Wnt/beta-catenin signalling in mesoderm development. Development. 2005;132:5375-85.

27. Merrill BJ, Gat U, DasGupta R, Fuchs E. Tcf3 and Lef1 regulate lineage differentiation of multipotent stem cells in skin. Genes Dev. 2001;15: $1688-705$

28. Yi F, Merrill BJ. Non-cell-autonomous stimulation of stem cell proliferation following ablation of Tcf3. Exp Cell Res. 2010;316:1050-60.

29. Ku AT, Shaver TM, Rao AS, Howard JM, Rodriguez CN, Miao Q, et al. TCF7L1 promotes skin tumorigenesis independently of beta-catenin through induction of LCN2. elife. 2017;6. https://doi.org/10.7554/eLife.23242.

\section{Ready to submit your research? Choose BMC and benefit from}

- fast, convenient online submission

- thorough peer review by experienced researchers in your field

- rapid publication on acceptance

- support for research data, including large and complex data types

- gold Open Access which fosters wider collaboration and increased citations

- maximum visibility for your research: over $100 \mathrm{M}$ website views per year

At BMC, research is always in progress.

Learn more biomedcentral.com/submissions 